HUOM! Tämä on alkuperäisen artikkelin rinnakkaistallenne. Rinnakkaistallenne saattaa erota alkuperäisestä sivutukseltaan ja painoasultaan.

Käytä viittauksessa alkuperäistä lähdettä:

Kauppinen, R. \& Drake, M. (2020). VIRTUAL REALITY IN COMPETENCE RECOGNITION FOR IMMIGRANTS. Teoksessa L. Gómez Chova, A. López Martínez, I. Candel Torres (Toim.).

INTED2020 : $14^{\text {th }}$ International Technology, Education and Development Conference, 2-4 March, 2020 - Valencia, spain (ss. 5578-5582). Valencia : IATED Academy. DOI: 10.21125/inted.2020.1515

PLEASE NOTE! This in an electronic self-archived version of the original article. This reprint may differ from the original in pagination and typographic detail.

Please cite the original version:

Kauppinen, R. \& Drake, M. (2020). VIRTUAL REALITY IN COMPETENCE RECOGNITION FOR IMMIGRANTS. In L. Gómez Chova, A. López Martínez, I. Candel Torres (Eds.). INTED2020 : $14^{\text {th }}$ International Technology, Education and Development Conference, 2-4 March, 2020 - Valencia, spain (pp. 5578-5582). Valencia : IATED Academy. DOI: 10.21125/inted.2020.1515

(C) 2020 IATED. 


\title{
VIRTUAL REALITY IN COMPETENCE RECOGNITION FOR IMMIGRANTS
}

\author{
R. Kauppinen ${ }^{1}$, M. Drake ${ }^{1}$ \\ ${ }^{1}$ Haaga-Helia University of Applied Sciences (FINLAND)
}

\begin{abstract}
VR (Virtual Reality) has been a trending technology in the recent years. It is already widely used, for example, in the fields of entertainment and design. The utilization of VR has also been explored from educational viewpoint in, for example simulation training in aviation and design and modelling in engineering while much of the current research focuses on the area of medicine.

From educational viewpoint, VR is also a promising tool for competence recognition, since it provides a way to create interactive virtual twins (virtual counterparts) of the real-life environments, objects and people as well as of the person whose competences are to be recognized. This way, it is possible to show and recognize the competencies such as the vocational ones needed in the working life by doing tasks where the competencies in question are actually used. The VR environment with the necessary digital twins can also provide guidance as needed. In addition, the environment can be designed as language independent relying non-linguistic methods, for example visuals instead of text, which helps to show and recognize competencies in situations where language barrier exists.

In this paper, we explore the possibilities in using VR in competence recognition for immigrants. The background for this is that immigrants will play a significant role in maintaining an adequate level of Finland's working-age population, since four out of five foreigners living in Finland are of working age. However, the employment rate of working-age immigrants is considerably lower than that of the general population and one of the biggest obstacles to employing immigrants is a lack of language skills. We present a way for developing a competence recognition model using VR to employ immigrants in a particular field. We will use work in the restaurant field as an example case and discuss what kind of competence recognition model best serves companies in this field in finding the persons with proper expertise.
\end{abstract}

Keywords: Virtual reality, competence recognition, digital twin, immigrants, vocational competencies.

\section{INTRODUCTION}

Our working environment is changing at accelerated pace and new skills and competences are needed at the working places. Finnish Ministry of Culture and Education [1] predicts that workplaces will play a significant role in competence recognition and workplaces need new ways to recognise competences. Therefore, we need to shape the politics of lifelong learning's core, which is expertise instead of degrees.

Also, immigrants will play a significantly increasing role in maintaining an adequate level of Finland's working-age population. Four of five foreigners who are living in Finland are of working age; however, the employment rate of working-age immigrants is considerably lower than that of the general population [2]. One of the biggest obstacles to employing immigrants is a lack of language skills. According to the OECD's (Organization for Economic Cooperation and Development) 2018 report [3], earlier attempts to employ and integrate immigrants in Finnish society have not been sufficient.

In the year 2019 the value of the VR (Virtual Reality) start-up companies was about 45 billion dollars [4]. Although the trend in investing on VR is downward the peak year being 2016 over 800 million dollars [5], it is currently widely used and provides also a way of supporting employment and integration of immigrants when applied to competence recognition and learning of working skills. VR has already been studied and adopted in areas such as computer science, engineering, psychology, geography, transportation and learning hands on skills on a construction business [6]-[9]. However, the most studied area, especially regarding competence recognition using VR, is medicine [10]-[12].

Our approach is to develop and test the use of VR in identifying the competencies needed in working life and in supporting employment training, especially for immigrants, so that 
language skills are a minimum constraint. The goal is also to increase the awareness of companies, including recruitment agencies, in using VR for recruiting, work training and task orientation. Our current focus here is especially service industry, for example restaurants, that differ in requirements regarding working skills and vocational competencies compared to the fields already studied.

Using VR is feasible, since VR is an immersive experience in which a person is deeply concentrated on his/her tasks and unaware of being in a virtual world. Immersion can help learning by reducing external distractions [9], [13], [14]. VR is also said to elaborate problemsolving capability and to improve learning engagement [15].

Kulik et al. [16] suggest that virtual learning should be highly interactive because people learn by doing. VR learning can include collaborative interaction with others if it can focus on the environment but learning also necessitates individual autonomy. Huang et al. [7] claim that VR learning enhances interpersonal communication as well as a service mind-set. The biggest obstacles to using VR are the cost and human resources [17]. However, decreasing software and equipment costs are making more experiments possible.

VR could be particularly useful for training immigrants, since VR provides a way to create interactive virtual twins (virtual counterparts) of the real-life environments, objects and people as well as of the person whose competences are to be recognized [18], [19]. So, it is possible to show and recognize the competencies such as the vocational ones needed in the working life by doing tasks where the competencies in question are actually used. Tasks can be repeated safely, and knowledge can also be verified on a virtual world screen. The VR environment with the necessary digital twins can also provide guidance as needed. Also, instructions need not necessarily be only linguistic. Instead, training modules can be produced, for example, so that the correct modes of action are firstly demonstrated before being practiced.

\section{METHODOLOGY}

Since we are developing a VR-based model for competence recognition together with immigrant organizations and entrepreneurs to open new employment avenues, the research method is based on the Living Lab approach, which is a user-centric ecosystem that aims to produce innovations, new products and new services in collaboration with users, citizens, companies and researchers [20]. The goals of the Living Lab are to solve everyday problems and to boost the economy by practice-based innovation, rapid development and testing of users [21]. The research data has been drawn from brainstorming, co-creation workshops and developing and testing workshops.

We are applying the Living Lab approach to the following research question: How to develop a competence recognition model using VR to employ immigrants in a particular field? To answer this question, we have taken first steps in order to build an ecosystem with companies, immigrant organizations, local employment authorities and educational institutions in Helsinki area between late 2019 and early 2020. Based on the early contacts we selected a relevant service-oriented field (restaurant), a representative company from the selected field having immediate need for new employees and a first group of immigrants found through the immigrant organizations, local employment authorities and educational institutions.

Using the living lab approach, we developed a preliminary model for competency recognition using VR in co-operation with the selected company and educational institutions. The model was used in recognizing the competencies of the first group of immigrants by using a proofof-concept level VR implementation focusing on one of the key competency area (hygiene) in the selected field. 


\section{RESULTS}

The results are discussed in two parts. First, we outline the findings on building a competency recognition model for VR implementation are outlined. Then, we cover our findings so far on building and using VR implementation for competency recognition.

\subsection{Building a competence recognition model}

As mentioned in Chapter 2, we built a competence recognition model applying Living Lab approach with a company in the need of employees and the educational institutions using the following steps: 1) Identify relevant stakeholders and interest groups, such as companies, immigrant organizations, local employment authorities and educational institutions in the area; 2) Select the stakeholders and interest groups for preliminary contacting and approach them; 3) Meet and brainstorm with the interested stakeholders and groups; 4) Select the focus field(s) and identify key competencies in these fields; 5) Define the levels of competencies selected and map them to the types of tasks in the VR implementation.

An example of a result on building a competence recognition model is seen in Table 1 where hygiene related competency recognition for restaurant work is modeled. The levels used are the first three levels in Bloom's taxonomy [22]. The competence for each level is described verbally and mapped into corresponding type of VR task.

Table 1. Competence recognition model for hygiene in restaurant work.

\begin{tabular}{l|c|c}
\hline \hline Level 1: & Competence & VR Task \\
\hline Knowledge & $\begin{array}{c}\text { Is able to identify faults in } \\
\text { hygiene in the restaurant } \\
\text { environment. }\end{array}$ & $\begin{array}{c}\text { Visual identification by } \\
\text { pointing out the faults in the } \\
\text { hygiene in the VR } \\
\text { restaurant environment. }\end{array}$ \\
\hline Covel 2: & $\begin{array}{c}\text { Is able to answer simple } \\
\text { questions related to } \\
\text { hygiene in the restaurant } \\
\text { environment. }\end{array}$ & $\begin{array}{c}\text { Answering true or false (or } \\
\text { multiple choice) questions } \\
\text { (text, voice and/or visual) in } \\
\text { the VR restaurant } \\
\text { environment by pointing the } \\
\text { right answers. }\end{array}$ \\
\hline Level 3: & $\begin{array}{c}\text { Is able to handle food } \\
\text { products according to } \\
\text { hygienic standards in the } \\
\text { restaurant environment. }\end{array}$ & $\begin{array}{c}\text { Carrying out a food } \\
\text { preparing task using the } \\
\text { available virtual twins in the } \\
\text { VR restaurant environment. }\end{array}$ \\
\hline \hline
\end{tabular}

\subsection{Virtual reality implementation}

Based on the competence recognition model discussed in Chapter 3.2, we also built a proofof-concept type of a VR implementation of the restaurant environment for Oculus Quest virtual glasses with Unity engine for level 2 (comprehension) competence and VR task in Table 1. A screenshot of the VR implementation illustrating an example question is shown in Fig. 1. 


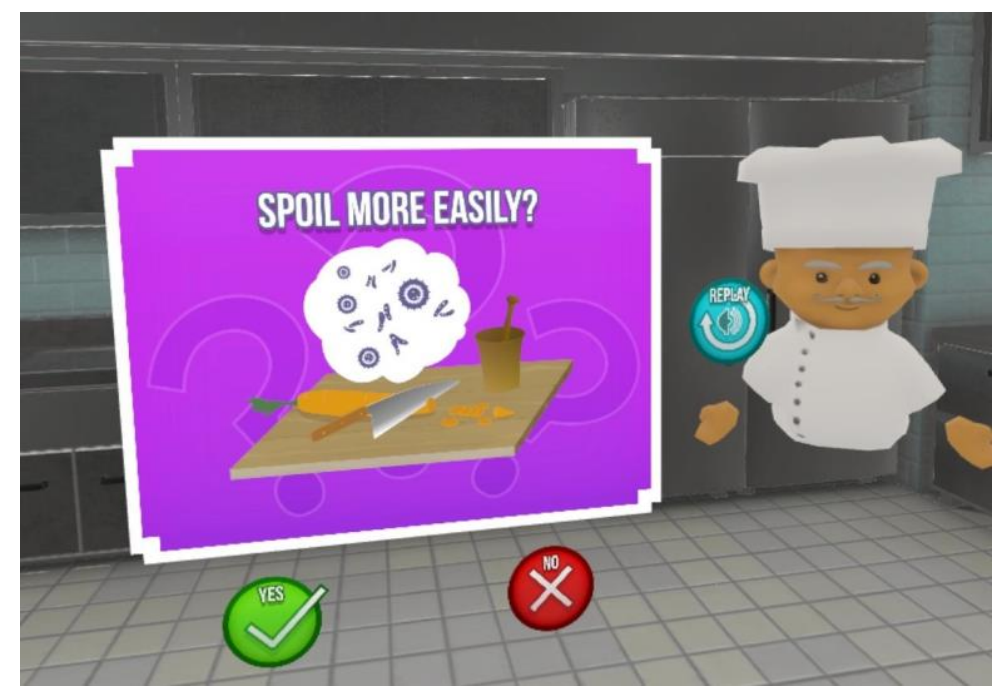

Figure 1. A screenshot from the VR implementation.

As can be seen in Fig. 1, the VR restaurant environment provides immersion reducing distractions and can provide visuals in order to rely not only to text. In addition, the questions are also read aloud to be less text-based. The answer is given by pointing at the selected choice and immediate feedback is provided. The questions in this VR implementation are based on the hygiene passport that is required for employees working with food products in Finland [23].

\section{CONCLUSIONS}

Overall, the approach described in this paper shoes promise, since it is possible to build a competence recognition model combining a selected taxonomy of competencies, defined key competencies from a selected field and corresponding VR tasks as shown in Chapter 3.1. Also, building a competency recognition model using Living Lab approach with relevant stakeholders and interest groups, in this case with a company in the need of employees and educational institutions having the knowledge in competence recognition, proved to be fruitful since the educational institutions could provide expertise on the competence recognition whereas the company provided information on the key working skills needed as well as on their specific environment. The Living Lab approach also supported continuous dialogue and possibility to gain necessary additional information from, for example, local employment authorities on employing immigrants.

Furthermore, as shown in Chapter 3.2, it is possible to implement VR tasks corresponding to the competencies and their levels. Again, the Living Lab approach is well suited here, since it is possible to create a VR environment and tasks based on the specific characteristics and needs of the stakeholders. However, creating the VR environment and stakeholder specific virtual twins requires development resources and the complexity of development rises in accordance to the levels of competencies, since higher levels competencies require more complex tasks to be performed. In the case of service industry, especially with small to medium sized enterprises as in this case, it may be feasible to focus on competence levels 1 and 2 first instead of aiming immediately to the higher-level task implementations.

In our future work, we plan to elaborate both the competence recognition model and the VR implementation. It is possible to expand the competency recognition model to cover more competencies and corresponding VR task types as well as different fields of competencies. In addition, different taxonomies of competencies could be used. Because of this, we also plan to define a metamodel for the VR-based competence recognition supporting this flexibility. 
In addition, we are expanding our Living Lab based approach to cover more stakeholders such as companies and additional groups of immigrants. This makes it possible to widen the user participation and get more feedback for further enhancing the competence recognition model and the VR implementation so that it will help the companies to be able to employ the most suitable candidates as well as provide more insight on what kind of competence recognition model and VR tasks best serve participating companies in finding the proper expertise and how satisfied are the participating immigrants and the company representatives with the competence recognition model and the VR implementation.

\section{ACKNOWLEDGEMENTS}

This work has been funded by European Social Fund.

\section{REFERENCES}

[1] Ministry of Education and Culture, “Jatkuvan oppimisen kehittäminen" (Developing lifelong learning), Publications of Ministry of Education and Culture, vol. 19, 2019. Retrieved from http://urn.fi/URN:ISBN:978-952-263-641-6

[2] A. Eronen, V. Härmälä, S. Jauhiainen, H. Karikallio, R. Karhinen, A. Kosunen, J-P. Laamanen, and M. Lahtinen, "Maahanmuuttajien työllistyminen. Taustatekijät, työnhaku ja työvoimapalvelut." (Labour Market of Immigrants in Finland), Publications of Ministry of Economic Affairs and Employment, vol. 6, 2014.

[3] Organization for Economic Co-operation and Development (OECD). Working Together: Skills and Labour Market Integration of Immigrants and their Children in Finland. Paris: OECD Publishing, 2018. Retrieved from https://doi.org/10.1787/9789264305250-en

[4] T. Merell, "VR AR Startup Valuation Reach 45 Billion \$ (on a paper)," Tech Crunch / Extra Crunch, 19 October, 2019. Retrieved from https://techcrunch.com/2019/10/18/vrar-startup-valuations-reach-45-billion-on-paper/

[5] A. Jenkins, "The Fall and Rise of VR. The Struggle to Make Virtual Reality Real," Fortune, 20 June, 2019. Retrieved from https://fortune.com/longform/virtual-realitystruggle-hope-vr/

[6] L. Freina and M. Ott, "A Literature Review on Immersive Virtual Reality in Education. The State of Art and Perspectives," in International Scientific Conference on eLearning and Software for Education, 2015. eLSE 2015. vol. 1, pp. 133-141, 2015.

[7] H-M. Huang, U. Rauch, and S-S. Liaw. "Investigating Learners' Attitudes Toward Virtual Reality Learning Environments: Based on a Constructivist Approach," Computers \& Education, vol. 55, no. 3, pp. 1171-1182, 2010.

[8] M. Melo, E. Bentley, K. McAllister, and J. Cortez, "Pedagogy of Productive Failure: Navigating the Challenges of Integrating VR into the Classroom," Journal of Virtual Worlds Research, vol. 12, no. 1, pp. 1-21, 2019.

[9] M. P. Wallach, R. Safir, E. Horef, E. Huber, and T. Heiman, "Presence in Virtual Reality. Importance and Methods to Increase It," Virtual Reality, March, 2012.

[10] R. Aggarwal, T. Grantcharov, K. Moorthy, J. Hance, and A. Darzi, "A CompetencyBased Virtual Reality Training Curriculum for the Acquisition of Laparoscopic Psychomotor Skill," The American Journal of Surgery, vol. 191, no. 1, pp. 128-133, 2006.

[11] C. Loukas, N. Nikiteas, M. Kanakis, and E. Georgiou, "Deconstructing Laparoscopic Competence in a Virtual Reality Simulation Environment," Surgery, vol. 149, no. 6, pp 750-760, 2011. 
[12] D. Ota, B. Loftin, T. Saito, R. Lea, and J. Keller, "Virtual Reality in Surgical Education," Computers in Biology and Medicine, vol. 25, no. 2, pp. 127-137, 1995.

[13] T. Parisi, Learning Virtual Reality: Developing Immersive Experiences and Applications for Desktop, Web, and Mobile. O'Reilly, 2015.

[14] B. Witmer, C. Jerome, and M. Singer, "The Factor Structure of the Presence Questionnaire," Presence, vol. 14, no. 3, pp. 298-312, 2005.

[15] L. Zheng, T. Xie, and G. Liu, "Affordance of Virtual Reality for Collaborative Learning," in International Joint Conference on Information, Media and Engineering, 2018. ICIME 2018. vol. 1, pp. 6-10, 2018.

[16] A. Kulik, A. Kunert, S. Beck, and B. Frölich, "Collaborative Virtual Reality for Joint Learning Experiences," in 12th International Conference on Computer Supported Collaborative Learning, 2017. CSCL 2017. vol. 1, pp. 721-722, 2017.

[17] S. Kavanagh, A. Luxton-Reilly, B. Wunche, and B. Plimmer, "A Systematic Review of Virtual Reality in Education," Themes in Science \& Technology Education, vol. 10, no. 2, pp. 85-119, 2017.

[18] M. Schluse and J. Rossmann, "From Simulation to Experimentable Digital Twins: Simulation-Based Development and Operation of Complex Technical Systems," in IEEE International Symposium on Systems Engineering, 2016. ISSE 2016. vol. 1, pp. 1-6, 2016.

[19] B. Schleicha, N. Anwer, L. Mathieu, and S. Wartzacka, "Shaping the Digital Twin for Design and Production Engineering," CIRP Annals, vol. 66, no. 1, pp. 141-144, 2017.

[20] H. W. Chesbrough. Open Innovation: The New Imperative for Creating and Profiting from Technology. Boston: Harvard Business School Press, 2003.

[21] M. Pallot, B. Trousse, B. Senach, and D. Scapin, "Living Lab Research Landscape: From User-Centered Design and User Experience towards User Cocreation," in First European Summer School 'Living Labs', 2010. Retrieved from https://hal.inria.fr/inria00612632

[22] W. Lorin and D. Krathwohl (eds.), A Taxonomy for Learning, Teaching, and Assessing: A Revision of Bloom's Taxonomy of Educational Objectives. New York: Longman, 2001.

[23] Finnish Food Authority, Hygiene Passport. Accessed 9 January, 2020. Retrieved from https://www.ruokavirasto.fi/en/private-persons/hygiene-passport/ 